\title{
Qualidade do leite cru refrigerado sob inspeção federal na região Nordeste
}

\author{
[Quality of bulk tank milk with federal inspection from the dairy industry in the \\ Brazilian Northeast] \\ A.C. Ribeiro Neto ${ }^{1}$, S.B.P. Barbosa ${ }^{2}$, R.B. Jatobá ${ }^{3}$, A.M. Silva ${ }^{1}$, C.X. Silva ${ }^{4}$, \\ M.J.A. Silva ${ }^{3}$, K.R. Santoro ${ }^{5}$ \\ ${ }^{1}$ Aluno(a) de pós-graduação - Universidade Federal Rural de Pernambuco, PE - Bolsista Capes \\ ${ }^{2}$ Universidade Federal Rural de Pernambuco - PE \\ ${ }^{3}$ Técnicas do laboratório PROGENE - Universidade Federal Rural de Pernambuco, PE \\ ${ }^{4}$ Aluna da graduação - Universidade Federal Rural de Pernambuco, PE \\ ${ }^{5}$ Universidade Federal Rural de Pernambuco - Unidade Acadêmica Garanhuns, PE
}

\begin{abstract}
RESUMO
Estudou-se a influência sazonal sobre a composição química, a contagem de células somáticas (CCS) e a contagem bacteriana total (CBT) de leite cru refrigerado em vários estados da região Nordeste. Os dados foram obtidos de 116.989 amostras de leite de tanques coletadas pelas indústrias com cadastro no serviço de inspeção federal. As amostras foram separadas em três períodos (I, II, III), de acordo com aplicação da Instrução Normativa-51 (IN-51). O teor de gordura, média de 3,7\%, foi o componente do leite que apresentou maior variação. Proteína e lactose tiveram amplitude de $0,04 \%$ entre os períodos e apresentaram médias de 3,2 e 4,4\%, respectivamente. Maiores valores de CCS foram observados entre os meses de maio e julho, 594,33 a 625,28 mil cel/mL, enquanto para CBT os maiores valores ocorreram nos meses de maio e junho, 1308,54 e 1333,83 UFC/mL. Observaram-se diferenças significativas nos componentes do leite entre os estados, principalmente no que se refere à qualidade higiênico-sanitária.
\end{abstract}

Palavras-chave: gordura, proteína, qualidade do leite

\begin{abstract}
The aim was to study seasonal influence on the chemical composition, somatic cell count (SCC) and total bacteria count (TBC) in bulk tank milk in the Brazilian Northeast. The data analyzed was obtained from 116.989 samples of bulk tank milk collected from industries that have an account at the Federal Inspection Service (FIS). The samples were separated into three periods (I,II,III), according to application of IN-51. PROC GLM was used to study the comparison of means by Duncan's test. The fat varied more, with an average of $3.66 \%$, protein and lactose had an amplitude of $0.04 \%$ between periods, and an average of 3.16 and $4.41 \%$, respectively. Higher values of SCC were observed in the months from May to July (594.33 to 625.28 thousand cells $/ \mathrm{mL}$ ), while in TBC the largest values occurred in May and June (1308.54 and 1333.83 CFU/mL). Significant differences in milk components between states were observed, especially with regard to hygienic quality. The chemical composition, SCC and TBC were influenced between periods and months of the year.
\end{abstract}

Keywords: fat, protein, milk quality

\section{INTRODUÇÃO}

O setor lácteo brasileiro tem grande importância para o segmento agropecuário.

Em 2010, segundo estatísticas do IBGE publicadas pela Zoccal (2012), foi estimado que, no Brasil, a produção chegasse a 30,7 bilhões de litros de leite, com perspectiva de aumento na produção para 2011 em 32,3 bilhões de litros, mantendo o país entre os cinco maiores produtores de leite do mundo. No entanto, uma característica marcante observada é que não existe um padrão definido de produção: há

Recebido em 27 de abril de 2011

Aceito em 9 de maio de 2012

E-mail: agenorcrneto@hotmail.com 
variações nas diferentes regiões relacionadas ao clima, ao manejo, à disponibilidade de mão de obra, ao preço do leite e de insumos, aos tipos de indústrias e aos produtos por elas produzidos.

O Ministério da Agricultura, Pecuária e Abastecimento (MAPA) estabeleceu o Programa Nacional de Melhoria da Qualidade do Leite (PNQL), que tem como suporte normas e padrões estabelecidos, os quais foram publicados na forma de Instrução Normativa (IN-51) (Brasil, 2002). Os parâmetros utilizados por essa instrução e adotados por programas de qualidade de leite no âmbito internacional são os teores de gordura, proteína e sólidos totais, a contagem de células somáticas (CCS) e a contagem bacteriana total (CBT), bem como a presença de resíduos de antibióticos. A composição química do leite, a CCS e a CBT sofrem alterações devido às diferenças de manejo nas propriedades, principalmente estágio de lactação, raça, alimentação, frequência de ordenha, obtenção e estocagem do leite, idade e saúde da vaca, estação do ano e clima (McCrae e Muir, 1995).

Um dos componentes do leite mais sujeitos a variações é o teor de gordura, e as variações nos teores de proteína são determinantes do rendimento industrial, segundo LindmarkMansson et al. (2003). De acordo com Reis et al. (2004), estão incluídos nessas variações fatores ambientais e de manejo, especialmente relacionados à nutrição, além de genéticos. Assim como a CCS, a CBT influencia negativamente os constituintes do leite, afetando a composição química e reduzindo o rendimento no processamento do leite.

Após a implantação da IN-51, a cadeia do leite sofreu muitas transformações, no entanto a qualidade do leite ainda não apresenta padrões de excelência internacionais, como reportado por Souza et al. (2008), Horst et al. (2008), Cassoli et al. (2008) e Barbosa et al. (2008) nas diferentes regiões do Brasil, apontando uma preocupação com a qualidade do leite no que se refere à CCS e à CBT.

$\mathrm{Na}$ região Nordeste do Brasil, a precipitação pode ser considerada a principal variável meteorológica, com regime de chuvas sazonal (Meneghetti e Ferreira, 2009). Trabalhos que analisaram a qualidade do leite, realizados em alguns estados da região Nordeste, assinalaram variação na composição química entre anos (Lira, 2007; Barbosa et al., 2008; Ribeiro Neto et al., 2010).

O objetivo do presente trabalho foi avaliar a qualidade do leite cru refrigerado sob inspeção federal de indústrias de vários estados da região Nordeste quanto à composição química, à CCS e à CBT.

\section{MATERIAL E MÉTODOS}

Os dados foram provenientes de amostras de leite de tanques coletadas pelas indústrias da região Nordeste que têm cadastro no serviço de inspeção federal (SIF), as quais foram analisadas mensalmente, seguindo os padrões recomendados pelo laboratório PROGENE. Segundo Cassoli et al. (2010), as amostras de composição química devem ser analisadas até o quinto dia após a coleta; já para a CBT, as amostras podem ser analisadas até sete dias, desde que sejam mantidas abaixo de $7^{\circ} \mathrm{C}$ e com conservantes. Foram utilizadas 116.989 amostras de leite referentes à composição, à CCS e à CBT, no período de julho de 2007 a junho de 2010, que corresponde à primeira fase de aplicação da IN-51 na região Nordeste do Brasil.

Visando manter a integridade das amostras desde a coleta até sua análise no PROGENE, foi utilizado o conservante bronopol (2-bromo2nitropropano-1,3diol) para amostras destinadas às análises de composição química e de CCS; para amostras destinadas à análise de CBT, foi utilizado o conservante azidiol (azida sódica $0,1 \%$ e cloranfenicol).

A composição química, os teores de gordura, proteína, lactose e sólidos totais foram determinados pelo equipamento Bentley 2000. O extrato seco desengordurado (ESD) foi calculado por diferença entre sólidos totais e gordura. A CCS e a CBT foram realizadas pelos equipamentos Somacount 300 e Bactocount IBC, respectivamente, Bentley Instruments, Inc. (2007).

Algumas restrições foram aplicadas aos dados para evitar possíveis ocorrências de vícios no processo de amostragem do leite, por meio de análises de frequência, PROC FREQ, SAS (Statistical..., 2002). Para os componentes de composição, foram consideradas amostras nos 
seguintes intervalos de valores, de acordo com o constituinte: gordura (de 2,00 a 7,60\%) e proteína (de 2,25 a 5,15\%). Para a CCS, foram consideradas amostras que apresentavam valores acima de 13.000, pois as transformações em escala logarítmica abaixo desse valor resultariam em valores negativos. Após essas restrições, foram utilizados 107.914 dados para desenvolvimento do estudo.

A CCS foi transformada em escore de células somáticas (ECCS), segundo Ali e Shook (1980) e Shook e Shutz (1994). Para os dados de CBT, foram realizadas transformações logarítmicas $\left(\mathrm{LOG}_{10}\right)$ na determinação do escore de bactérias totais (ECBT) (Bueno, 2008). Essas transformações são importantes porque facilitam a interpretação dos resultados, pois cada unidade de escore representa uma escala de variação nos números de CCS e CBT.

Com o objetivo de avaliar a primeira fase de aplicação da IN-51 no Nordeste, as amostras foram separadas por períodos, da seguinte forma: período I: amostras coletadas de julho/2007 a junho/2008; período II: amostras coletadas de julho/2008 a junho/2009; período III: amostras coletadas de julho/2009 a junho/2010.

Os dados foram analisados segundo o modelo: $\hat{Y}_{i j k}=\mu+M_{i}+P_{j}+E_{k}+P_{x} E_{j k}+e_{i j k}$, em que: $\hat{\mathrm{Y}}_{(\mathrm{ijk})}=$ observações referentes aos dados de amostras do leite cru; $\mu=$ constante inerente a todas as observações; $\mathrm{MC}_{(\mathrm{i})}=\mathrm{i}^{-}{ }^{\text {ésimo }}$ efeito do mês de coleta da amostra, sendo $\mathrm{i}=1$ a $12 ; \mathrm{P}_{(\mathrm{j})}=$ j- ${ }^{-}{ }^{-1 i m o}$ efeito do período de aplicação da IN-51,

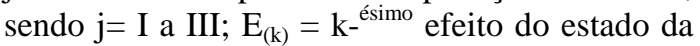
Federação de coleta da amostra, sendo $\mathrm{k}=1$ a 9; $\mathrm{P} \times \mathrm{E}_{(\mathrm{jk})}=$ efeito de interação estado $\mathrm{x}$ período; $\mathrm{e}_{(\mathrm{ijk})}=$ erro aleatório associado a cada observação $\hat{\mathrm{Y}}_{\text {(ijk). }}$ Os dados foram analisados utilizando-se o PROC GLM (Statistical..., 2002)) e o teste de Duncan para comparação de médias.

\section{RESULTADOS E DISCUSSÃO}

Na Tab. 1, está o número de amostras analisadas por período de aplicação da IN-51 e, na Tab. 2, o número de amostras analisadas segundo o estado da região Nordeste.

Na Tab. 3, estão descritas as médias para os constituintes de composição do leite, CCS e CBT, observadas na primeira fase de aplicação da IN-51 no Nordeste.

O número de amostras foi crescente, principalmente, do I ao II período (Tab. 1), o que reflete, provavelmente, maior conhecimento e aceitação por parte da indústria leiteira da IN-51. Essa tendência de aumento no número de amostras analisadas também foi observada por Fonseca et al. (2008) e Souza et al. (2008), em Minas Gerais, em diferentes laboratórios da Rede Brasileira de Laboratórios de Controle da Qualidade do Leite (RBQL), e por Cassoli et al. (2008), em São Paulo.

Tabela 1. Número de amostras analisadas para composição química, contagem de células somáticas e contagem bacteriana total, no PROGENE, de acordo com o período da IN-51 considerado

\begin{tabular}{cccc}
\hline Período & I & II & III \\
\hline Composição química & 5062 & 15263 & 16028 \\
CCS & 5110 & 15441 & 16189 \\
CBT & 2878 & 14913 & 17030 \\
\hline Total & 13050 & 45617 & 49247 \\
\hline
\end{tabular}

Tabela 2. Número de amostras da composição química, da contagem de células somáticas (CCS) e da contagem bacteriana total (CBT), segundo o estado da região Nordeste

\begin{tabular}{cccc}
\hline Estado & Composição química & CCS & CBT \\
\hline AL & 5446 & 5483 & 5321 \\
BA & 687 & 688 & 737 \\
CE & 7192 & 7172 & 6568 \\
MA & 1564 & 1704 & 1423 \\
PB & 4710 & 4789 & 4553 \\
PE & 10868 & 10898 & 10809 \\
PI & 1893 & 1920 & 1813 \\
RN & 3081 & 3168 & 2769 \\
SE & 912 & 918 & 828 \\
\hline
\end{tabular}


Tabela 3. Médias, desvios-padrão e coeficiente de variação da composição química do leite, da contagem de células somáticas e da contagem bacteriana total dos dados analisados na primeira fase da IN-51 na região Nordeste

\begin{tabular}{lccc}
\hline Componente & $\mathrm{n}$ & Média $\pm \mathrm{DP}$ & $\mathrm{CV}(\%)$ \\
\hline Gordura $^{1}$ & 36353 & $3,66 \pm 0,53$ & 14,44 \\
Proteína $^{1}$ & 36353 & $3,16 \pm 0,22$ & 6,88 \\
Lactose $^{1}$ & 36353 & $4,41 \pm 0,18$ & 4,16 \\
ST $^{1}$ & 36353 & $12,10 \pm 0,66$ & 5,46 \\
ESD $^{1}$ & 36353 & $8,44 \pm 0,33$ & 3,89 \\
CCS $^{2}$ & 36741 & $564,95 \pm 653,56$ & 115,68 \\
CBT $^{3}$ & 34821 & $1190,68 \pm 1384,65$ & 116,29 \\
\hline
\end{tabular}

${ }^{1}$ Valores expressos em g/100g; ${ }^{2} \mathrm{X} 1000 \mathrm{cel} / \mathrm{mL} ;{ }^{3} \mathrm{X} 1000 \mathrm{UFC} / \mathrm{mL}$.

DP: desvio-padrão.

As médias dos teores dos constituintes de composição foram semelhantes às encontradas em diversos trabalhos realizados no país, com pequenas variações: Ribas et al. (2004), Lima et al. (2006), Lira (2007) e Dürr et al. (2003), para gordura; Durães et al. (2001) e Lima et al. (2006), para proteína; Fernandes et al. (2004), Lima et al. (2006) e Machado et al. (2000), para lactose; Durães et al. (2001) e Machado et al. (2000), para sólidos totais.

A média de CCS (Tab. 3), embora superior, é próxima às médias relatadas por Paula et al. (2004), de 486,81 $\times 10^{3} \mathrm{cel} / \mathrm{mL}$, e por Machado et al. (2000), de 505.000 \pm 593.000 células $/ \mathrm{mL}$. Elevada CCS geralmente sugere perdas significativas na produção, baixo rendimento do leite, diminuição da vida útil do produto processado, enquanto a manutenção de baixa CCS é indicativo de boa saúde da glândula mamária dos animais do rebanho (Schukken et al., 1990). A média de CCS encontrada nas análises em estudo sugerem a presença de mastite subclínica nos rebanhos.

Já o valor médio de $1190,68 \times 10^{3} \pm 1384,6$ $\mathrm{UFC} / \mathrm{mL}$, para CBT, é bem mais elevado que os valores relatados por Mesquita et al. (2006), em Goiás, Fonseca et al. (2006), em Minas Gerais, e Machado et al. (2006), em São Paulo, refletindo em péssimas condições higiênicas do leite destinado às indústrias e aos laticínios e em pouca ou nenhuma manutenção nos tanques de resfriamento. Como consequência, o leite com elevada CBT pode causar acidez, queda no rendimento e deterioração dos derivados.
Observa-se, na Tab. 3, que o teor de gordura é o constituinte do leite que apresentou o coeficiente de variação mais elevado (14,44\%). Segundo Reis et al. (2004), esse componente sofre influência de fatores ambientais e de manejo, especialmente relacionados à nutrição, além de fatores genéticos.

$\mathrm{Na}$ Tab. 4, estão as médias ajustadas para teores de gordura, proteína, ESD, CCS e CBT.

Maiores teores de gordura foram observados nos meses de abril e maio; os teores de proteína e ESD foram mais elevados no mês de maio (Tab. 4), que coincide com os meses mais chuvosos. Os menores teores de gordura e proteína foram registrados nos meses mais secos do ano, de setembro a dezembro (Tab. 4). Já o ESD apresentou menor teor no mês de março (Tab. 4). Esses resultados provavelmente e principalmente refletem disponibilidade de alimentos e manejo alimentar oferecidos aos animais durante os dois períodos distintos. Tais variações são justificadas pelas diferenças na pluviometria e na temperatura ambiente entre os meses, que influenciam diretamente o consumo de matéria seca e o metabolismo, bem como pela qualidade das forragens disponíveis (Staines et al., 2000). Segundo Silva et al. (2011), a estação chuvosa em todos os estados do Nordeste brasileiro culmina nos meses de março, abril e maio (trimestre chuvoso), apresentando volume de chuva também nos meses de outubro, novembro e dezembro; no entanto, por influência de fenômenos atmosféricos, esse comportamento varia em intensidade nos estados da região, conforme observado na Fig. 1. 
Tabela 4. Médias ajustadas dos teores de gordura, proteína e extrato seco desengordurado, da contagem de células somáticas e da contagem bacteriana total, de acordo com o mês de coleta do leite

\begin{tabular}{lccccc}
\hline Mês & $\begin{array}{c}\text { Gordura } \\
(\%)\end{array}$ & $\begin{array}{c}\text { Proteína } \\
(\%)\end{array}$ & $\begin{array}{c}\text { ESD } \\
(\%)\end{array}$ & $\begin{array}{c}\text { CCS } \\
(1000 \mathrm{cel} / \mathrm{mL})\end{array}$ & $\begin{array}{c}\text { CBT } \\
(1000 \mathrm{UFC} / \mathrm{mL})\end{array}$ \\
\hline Janeiro & $3,55 \pm 0,45 \mathrm{e}$ & $3,12 \pm 0,22 \mathrm{~g}$ & $8,41 \pm 0,34 \mathrm{de}$ & $543,04 \pm 613,49 \mathrm{de}$ & $1252,78 \pm 1403,34 \mathrm{~b}$ \\
Fevereiro & $3,70 \pm 0,55 \mathrm{c}$ & $3,16 \pm 0,22 \mathrm{e}$ & $8,41 \pm 0,35 \mathrm{ef}$ & $494,57 \pm 556,66 \mathrm{f}$ & $1276,76 \pm 1448,06 \mathrm{ab}$ \\
Março & $3,69 \pm 0,53 \mathrm{c}$ & $3,18 \pm 0,20 \mathrm{~d}$ & $8,36 \pm 0,35 \mathrm{~g}$ & $540,57 \pm 570,87 \mathrm{de}$ & $1231,66 \pm 1376,21 \mathrm{~b}$ \\
Abril & $3,77 \pm 0,51 \mathrm{a}$ & $3,19 \pm 0,22 \mathrm{~cd}$ & $8,43 \pm 0,32 \mathrm{de}$ & $587,95 \pm 619,08 \mathrm{bc}$ & $1248,79 \pm 1410,25 \mathrm{~b}$ \\
Maio & $3,76 \pm 0,48 \mathrm{a}$ & $3,23 \pm 0,21 \mathrm{a}$ & $8,54 \pm 0,30 \mathrm{a}$ & $594,33 \pm 644,17 \mathrm{abc}$ & $1333,83 \pm 1522,91 \mathrm{a}$ \\
Junho & $3,73 \pm 0,53 \mathrm{~b}$ & $3,21 \pm 0,21 \mathrm{~b}$ & $8,48 \pm 0,32 \mathrm{~b}$ & $625,28 \pm 737,76 \mathrm{a}$ & $1308,54 \pm 1394,57 \mathrm{ab}$ \\
Julho & $3,74 \pm 0,56 \mathrm{~b}$ & $3,20 \pm 0,20 \mathrm{cb}$ & $8,43 \pm 0,31 \mathrm{~d}$ & $609,73 \pm 695,20 \mathrm{ab}$ & $1122,92 \pm 1277,65 \mathrm{c}$ \\
Agosto & $3,68 \pm 0,53 \mathrm{c}$ & $3,15 \pm 0,19 \mathrm{f}$ & $8,47 \pm 0,32 \mathrm{~b}$ & $586,37 \pm 624,40 \mathrm{bc}$ & $912,49 \pm 1158,80 \mathrm{~d}$ \\
Setembro & $3,61 \pm 0,51 \mathrm{~d}$ & $3,09 \pm 019 \mathrm{~h}$ & $8,41 \pm 0,29 \mathrm{ef}$ & $537,49 \pm 629,51 \mathrm{de}$ & $1106,20 \pm 1295,62 \mathrm{c}$ \\
Outubro & $3,51 \pm 0,52 \mathrm{f}$ & $3,10 \pm 0,20 \mathrm{~h}$ & $8,45 \pm 0,30 \mathrm{c}$ & $549,42 \pm 630,61 \mathrm{~d}$ & $1111,57 \pm 1362,03 \mathrm{c}$ \\
Novembro & $3,52 \pm 0,51 \mathrm{f}$ & $3,09 \pm 0,21 \mathrm{~h}$ & $8,42 \pm 0,32 \mathrm{de}$ & $561,13 \pm 794,28 \mathrm{~cd}$ & $1072,50 \pm 1368,61 \mathrm{c}$ \\
Dezembro & $3,53 \pm 0,50 \mathrm{ef}$ & $3,09 \pm 0,23 \mathrm{~h}$ & $8,40 \pm 0,33 \mathrm{f}$ & $511,13 \pm 696,35 \mathrm{ef}$ & $1129,73 \pm 1399,00 \mathrm{c}$ \\
\hline
\end{tabular}

Letras distintas na coluna indicam diferenças pelo teste de Duncan $(\mathrm{P}<0,05)$.

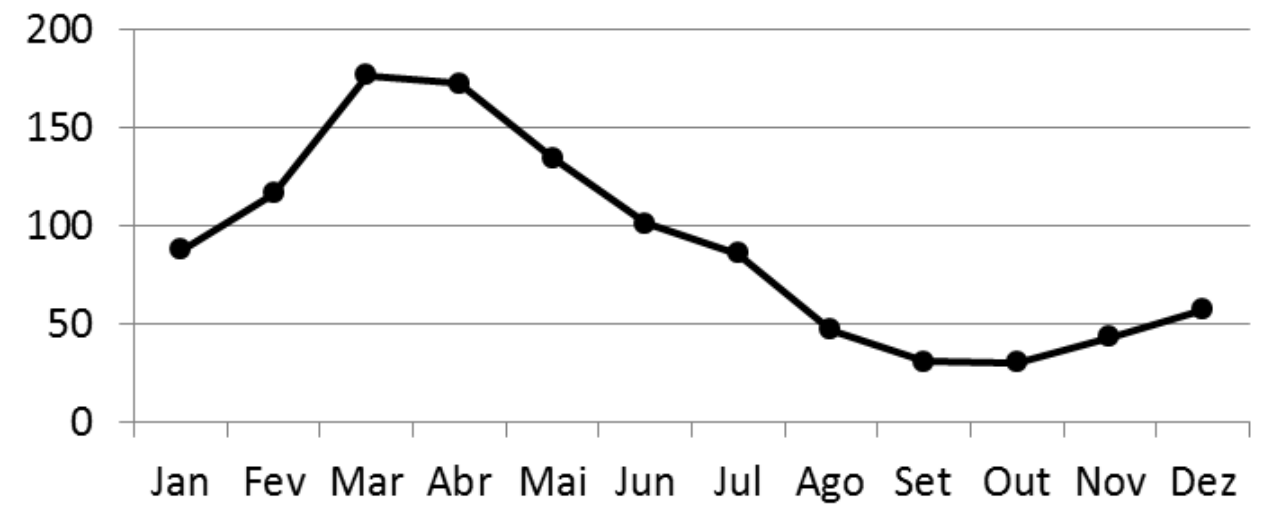

Figura 1. Precipitação pluvial média na região Nordeste.

Para as médias de CCS, maiores valores foram observados nos meses de junho e julho (Tab. 4), que correspondem ao período de transição entre chuvas e seca na região. Já as menores médias foram observadas nos meses de transição entre os períodos de seca e chuva, dezembro e fevereiro. A despeito dessas diferenças retratadas ao longo do ano, essas médias mensais sugerem presença de leite contaminado na indústria, pois são um

indicativo de vacas com mastite subclínica.

As maiores médias de CBT foram mais evidentes nos meses mais chuvosos, o que era de se esperar, em razão dos altos índices pluviométricos que ocorrem na estação, propiciando alta umidade. De acordo com Bueno et al. (2008), o período das chuvas favorece o aumento da contaminação ambiental, o acúmulo de lama nas instalações e a maior ocorrência de tetos sujos no momento da ordenha.

$\mathrm{Na}$ Tab. 5, estão os valores médios dos constituintes da composição do leite, da CCS e da CBT, de acordo com o período de aplicação da IN-51. 
Tabela 5. Médias ajustadas da composição química do leite, da contagem de células somáticas e da contagem bacteriana total, de acordo com o período de aplicação da IN-51

\begin{tabular}{lccc}
\hline \multirow{2}{*}{ Componente } & $\begin{array}{c}\text { I } \\
\text { (Julho/2007 a junho/2008) }\end{array}$ & $\begin{array}{c}\text { II } \\
\text { (Julho/2008 a junho/2009) }\end{array}$ & $\begin{array}{c}\text { III } \\
\text { (Julho/2009 a junho/2010) }\end{array}$ \\
\cline { 2 - 4 } & Média $\pm d p$ & Média $\pm d p$ & Média $\pm d p$ \\
\hline Gordura $^{1}$ & $3,72 \pm 0,59 \mathrm{a}$ & $3,60 \pm 0,55 \mathrm{c}$ & $3,69 \pm 0,48 \mathrm{~b}$ \\
Proteína $^{1}$ & $3,13 \pm 0,22 \mathrm{c}$ & $3,15 \pm 0,23 \mathrm{~b}$ & $3,17 \pm 0,20 \mathrm{a}$ \\
Lactose $^{1}$ & $4,37 \pm 0,17 \mathrm{c}$ & $4,41 \pm 0,19 \mathrm{a}$ & $4,40 \pm 0,18 \mathrm{~b}$ \\
ST $^{1}$ & $12,11 \pm 0,72 \mathrm{a}$ & $12,08 \pm 0,69 \mathrm{~b}$ & $12,12 \pm 0,61 \mathrm{a}$ \\
ESD $^{1}$ & $8,39 \pm 0,30 \mathrm{c}$ & $8,47 \pm 0,34 \mathrm{a}$ & $8,42 \pm 0,32 \mathrm{~b}$ \\
$\mathrm{CCS}^{2}$ & $511,78 \pm 661,57 \mathrm{c}$ & $535,51 \pm 636,09 \mathrm{~b}$ & $609,86 \pm 664,54 \mathrm{a}$ \\
ECCS & $4,23 \pm 1,92 \mathrm{c}$ & $4,61 \pm 1,66 \mathrm{a}$ & $4,46 \pm 2,04 \mathrm{~b}$ \\
CBT $^{2}$ & $1367,10 \pm 1529,3 \mathrm{a}$ & $1161,46 \pm 1430,69 \mathrm{~b}$ & $1186,45 \pm 1314,06 \mathrm{~b}$ \\
ECBT & $2,78 \pm 0,66 \mathrm{a}$ & $2,67 \pm 0,69 \mathrm{~b}$ & $2,77 \pm 0,57 \mathrm{a}$ \\
\hline
\end{tabular}

Letras distintas na linha indicam diferenças pelo teste de Duncan $(\mathrm{P}>0,05)$.

${ }^{1}$ Valores expressos em porcentagem; ${ }^{2} \mathrm{x} 1000 \mathrm{cel} / \mathrm{mL}$.

Com relação aos constituintes da composição química do leite, com exceção da proteína, que apresentou crescimento linear entre os períodos considerados, todos os outros apresentaram resultados médios aleatórios, sem nenhuma tendência definida. Considerando-se a expectativa de que o PNQL é um programa que, em um futuro próximo, possibilitará o pagamento do leite por qualidade, nesse primeiro período de aplicação da IN-51 ficou clara a pouca preocupação dos agentes da produção leiteira (produtores e indústrias) em melhorar a qualidade da matéria-prima. Cassoli et al. (2008), em São Paulo, e Horst et al. (2008), no Paraná, observaram tendência de aumento para os teores de gordura e proteína na primeira fase de aplicação da IN-51 naqueles estados, de 2005 a 2008. Essas diferenças podem estar relacionadas às diferenças regionais de produção e aceitação e de conhecimento da IN-51.

Com relação aos aspectos higiênico-sanitários, observou-se que a CCS apresentou crescimento linear com o passar dos períodos de aplicação da IN-51, enquanto a CBT apresentou tendência de redução. Os números, tanto da CCS quanto da CBT, são preocupantes, pois o primeiro reflete a condição sanitária dos rebanhos, implicando índices de mastite subclínica, e o segundo, a despeito da tendência de redução de acordo com os três períodos considerados, indica um leite de higiene não satisfatória. Elevada CCS é indicativo da ocorrência da mastite, trazendo grandes prejuízos ao produtor de leite, à indústria de laticínios e aos consumidores (Behmer, 1999).
De acordo com Bramley e Mckinnon (1990), amostras de leite com CBT acima de $100.000 \mathrm{UFC} / \mathrm{mL}$ indicam sérias falhas de higiene na produção, enquanto resultados inferiores a $20.000 \mathrm{UFC} / \mathrm{mL}$ refletem boas práticas de higiene. A presença de bactérias patogênicas no leite cru é uma preocupação de saúde pública, sendo um risco potencial para quem o consome diretamente ou na forma de seus derivados, e mesmo para quem o manuseia. O leite cru contaminado pode ser, ainda, fonte de contaminação cruzada para os produtos lácteos processados, pela contaminação do ambiente na indústria (Arcuri et al., 2006).

$\mathrm{Na}$ Tab. 6, estão as médias ajustadas dos constituintes do leite, da CCS e da CBT, de acordo com o estado da Federação do Nordeste onde foi coletada a amostra.

As diferenças climáticas e as práticas de manejo alimentar adotadas nas fazendas podem ter refletido diretamente na composição química do leite, o que implicou diferenças significativas entre os estados. Segundo Silva et al. (2011), a estação chuvosa em todos os estados do Nordeste brasileiro culmina nos meses de março, abril e maio (trimestre chuvoso), podendo apresentar, às vezes, volume de chuva também nos meses de outubro a dezembro; no entanto, por influência de fenômenos atmosféricos, esse comportamento varia em intensidade nos estados da região, afetando os componentes do leite, conforme descrito na Tab. 6. 
Tabela 6. Composição química da contagem de células somáticas, escore da contagem de células somáticas, da contagem bacteriana total e do escore da contagem bacteriana total do leite cru inspecionado segundo o estado da Federação onde ocorreu a coleta da amostra

\begin{tabular}{lccccccc}
\hline \multirow{2}{*}{ Estado } & \multicolumn{7}{c}{ Componente } \\
\cline { 2 - 7 } & Gordura(\%) & Proteína(\%) & ESD(\%) & CCS* & ECCS & CBT* & ECBT \\
\hline AL & $3,63 \mathrm{e}$ & $3,14 \mathrm{ef}$ & $8,42 \mathrm{~d}$ & $590,21 \mathrm{~cd}$ & 5,25 & $1142,22 \mathrm{~d}$ & 2,79 \\
$\mathrm{BA}$ & $3,75 \mathrm{bc}$ & $3,23 \mathrm{c}$ & $8,50 \mathrm{~b}$ & $551,89 \mathrm{de}$ & 4,84 & $990,05 \mathrm{e}$ & 2,79 \\
$\mathrm{CE}$ & $3,69 \mathrm{~d}$ & $3,13 \mathrm{f}$ & $8,38 \mathrm{e}$ & $516,06 \mathrm{e}$ & 4,77 & $1619,60 \mathrm{a}$ & 2,94 \\
MA & $3,72 \mathrm{~cd}$ & $3,33 \mathrm{a}$ & $8,78 \mathrm{a}$ & $472,24 \mathrm{f}$ & 4,48 & $1460,93 \mathrm{~b}$ & 2,84 \\
PB & $3,60 \mathrm{e}$ & $3,13 \mathrm{f}$ & $8,42 \mathrm{~d}$ & $534,21 \mathrm{e}$ & 4,70 & $1129,49 \mathrm{~d}$ & 2,69 \\
PE & $3,57 \mathrm{f}$ & $3,15 \mathrm{e}$ & $8,44 \mathrm{c}$ & $529,40 \mathrm{e}$ & 4,85 & $997,08 \mathrm{e}$ & 2,58 \\
PI & $3,72 \mathrm{~cd}$ & $3,18 \mathrm{~d}$ & $8,45 \mathrm{c}$ & $837,68 \mathrm{a}$ & 5,41 & $1135,14 \mathrm{~d}$ & 2,80 \\
RN & $3,86 \mathrm{a}$ & $3,17 \mathrm{~d}$ & $8,45 \mathrm{c}$ & $677,84 \mathrm{~b}$ & 5,01 & $1027,73 \mathrm{e}$ & 2,68 \\
SE & $3,77 \mathrm{~b}$ & $3,26 \mathrm{~b}$ & $8,49 \mathrm{~b}$ & $601,02 \mathrm{c}$ & 4,85 & $1344,24 \mathrm{c}$ & 2,84 \\
\hline
\end{tabular}

Letras distintas na coluna indicam diferenças pelo teste de Duncan $(\mathrm{P}<0,05)$.

* (x 1000 cels $/ \mathrm{mL})$.

No que se refere à incidência de mastite, maior valor de CCS foi observado no estado do Piauí (837.680cel/mL \pm 928.010 ), enquanto o estado do Maranhão apresentou a menor quantidade de células somáticas presentes por $\mathrm{mL}$ de leite

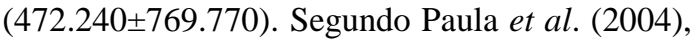
efeitos de microrregião, ano e mês de análise são significativos sobre a CCS. Para a CBT, com exceção dos estados de Pernambuco e Bahia, todos os outros apresentaram valores acima de 1.000.000UFC/mL.

A ocorrência de resultados elevados pode indicar existência de falhas generalizadas nos procedimentos de ordenha e refrigeração do leite nas propriedades leiteiras. Em rebanhos que apresentam CCS acima de 500.000 células $/ \mathrm{mL}$, há estimativa de perdas na ordem de $6 \%$ na produção leiteira (National..., 1996).

\section{CONCLUSÕES}

A composição química do leite, quanto aos teores de gordura, proteína, lactose, extrato seco total e extrato seco desengordurado, à contagem de células somáticas e à contagem bacteriana total, sofreu influência significativa do período de aplicação da IN-51, do mês de coleta da amostra e do estado da Federação onde foram coletadas as amostras. Essas variáveis causais devem ser consideradas quando da avaliação da qualidade do leite na região Nordeste.

\section{REFERÊNCIAS}

ALI, A.K.A.; SHOOK, G.E. An optimum transformation for somatic cell concentration in milk. J. Dairy Scie., v.63, p.487-90, 1980.

ARCURI, E.F.; BRITO, M.A.V.P.; BRITO, J.R.F. et al. Qualidade microbiológica do leite refrigerado nas fazendas. Arq. Bras. Med. Vet. Zootec., v.58, p.440-446, 2006.

BARBOSA, S.B.P.; JATOBÁ, R.B.; BATISTA, A.M.V. A Instrução Normativa 51 e a qualidade do leite na região Nordeste e nos estados do Pará e Tocantins. In: CONGRESSO BRASILEIRO DE QUALIDADE DO LEITE, 3., 2008, Recife. Anais... Recife-PE, 2008.

BEHMER, M.L.A. Tecnologia do leite. 13.ed. São Paulo: Editora Noel, 1999. Revista Balde Branco, no 143, março de 1999.

BENTLEY INSTRUMENTS, INC., Bentley Sistema Combinado 2300, Manual do Usuário, Versão 1.0, Escrito por Jeffrey Koch, Traduzido e Adaptado por Rafael Castilha. Publicado 1994. Traduzido e Adaptado 2007.

BRAMLEY, A.J.; McKINNON, C.H. The microbiology of raw milk. In: ROBINSON, R.K. Dairy Microbiology: The microbiology of milk. 2.ed. Barking: Elsevier Science Publishers, 1990. p.163-208. 
BRASIL. Instrução Normativa n. 51, de 18 de setembro de 2002. Regulamentos técnicos de produção, identidade e qualidade, coleta e transporte de leite. Brasília, DF: Ministério da Agricultura, Secretaria de Inspeção de Produto Animal, 2002, 39p.

BUENO,V.F.F.; MESQUITA, A.J.;NICOLAU, et al Contagem bacteriana total do leite: relação com a composição centesimal e período do ano no Estado de Goiás. Rev. Bras. Cienc. Vet., v.15, p.40-44, 2008.

CASSOLI, L.D.; MACHADO, P.F.; CARDOSO, F. Diagnóstico da qualidade do leite na região Sudeste entre 2005 e 2008. In: Congresso Brasileiro de Qualidade do Leite, 3., 2008, Recife. Anais... Recife-PE, 2008.

CASSOLI, L.D.; MACHADO, P.F.; COLDEBELLA, A. Métodos de conservação de amostras de leite para determinação da contagem bacteriana total por citometria de fluxo. Rev. Bras. Zootec., v.39, p.434-439, 2010.

DURÃES, M.S.; FREITAS, A.R.; COSTA, C.N. Influência da raça e do touro na qualidade do leite. Rev. Balde Branco, p.36-42. 2001.

DÜRR, J.W. Panorama da qualidade do leite na região Sul $(R S)$. In: BRITO, J.R.F e PORTUGAL, J.A.B. (Eds). Diagnóstico da qualidade do leite, impacto para industria e a questão dos resíduos de antibióticos. Juiz de Fora: EMBRAPA, 2003, 168f.

FERNANDES, A.M.; OLIVEIRA, C.A.F.; TAVOLARO, P. Relação entre a contagem de células somáticas e a composição do leite individual de vacas holandesas. Arq. Inst. Biol., v.71, p.163-166, 2004.

FONSECA, L.M.; RODRIGUES, R.; CERQUEIRA, M.M.O.P. et al. (2006). Situação da qualidade do leite cru em Minas Gerais. In: MESQUITA, A.J., DÜRR, J.W., COELHO, K.O. Perspectivas e avanços da qualidade do leite no Brasil. Goiânia: Talento, 2006. 352p.

FONSECA, L.M.; RODRIGUES, R.; CERQUEIRA, M.M.O.P. et al. Situação da qualidade do leite cru em Minas Gerais2007/2008. In. Congresso Brasileiro de Qualidade do Leite, 3., 2008, Recife. Anais... Recife, 2008, 373p.
HORST, J.A.; VALLOTO, A.A.; Qualidade do leite analisado no laboratório do Paraná - IN51/2002. In: Congresso Brasileiro de Qualidade do Leite, 3., 2008, Recife. Anais... Recife-PE, 2008.

LIMA, M.C.G.; SENA, M.J.; MOTA, R.A. et al. Contagem de células somáticas e análises físicoquímicas e microbiológicas do leite cru tipo c produzido na Região Agreste do Estado de Pernambuco. Arq. Inst. Biol., v.73, p.89-95, 2006.

LINDMARK-MANSSON，H.; FONDÉN， R.; PETTERSON, H.E. Composition of Swedish dairy milk. Int. Dairy J., v.13, p.409-425, 2003.

LIRA, A.V. Contagem de células somáticas e Composição do leite cru resfriado nos estados da Paraíba, Pernambuco e Rio Grande do Norte. 2007. 56f. Dissertação de Mestrado Universidade Federal Rural de Pernambuco.

MACHADO, P.F., CASSOLI, L.D. Diagnóstico da qualidade do leite na Região Sudeste. In: MESQUITA, A.J., DÜRR, J.W., COELHO, K.O. Perspectivas e avanços da qualidade do leite no Brasil. Goiânia: Talento, 2006. 352p. 2006.

MACHADO, P.F.; PEREIRA, A.R.; SARRIÉS, G.A. Efeitos da contagem de células somáticas na qualidade do leite e a atual situação de rebanhos leiteiros. Rev. Inst. "Cândido Tostes", v.54, p.10-16. 2000.

McCRAE, C.H.; MUIR, D.D. Heat stability of milk. In: HEAT- Induced changes in milk. 2nd. ed. Brussels: IDF, 1995, p.206-230.

MENEGHETTI, G.T.; FERREIRA, N.J., Variabilidade sazonal e interanual da precipitação no Nordeste Brasileiro. In: Simpósio Brasileiro de Sensoriamento Remoto, 14., 2009, Natal. Anais... Natal, 2009. p.1685-1689.

MESQUITA, A.J.; NEVES, R.B.S.; COELHO, K.O. et al.. A qualidade do leite na região Centro-Oeste. In: MESQUITA, A.J., DÜRR, J.W., COELHO, K.O. Perspectivas e avanços da qualidade do leite no brasil. Goiânia: Talento. 2006. 352p.

NATIONAL Mastitis Council. Current Concepts of Bovine Mastitis. In: MADISON, WI. Natl. Mastitis Council, 1996, p.40-41. 
PAULA, M.C.; RIBAS, N.P.; MONARDES, H.G. et al. Contagem de Células Somáticas em Amostras de Leite. Rev. Bras. Zootec., v.33, p.1303-1308, 2004.

REIS, R.B.; GLÓRIA J.R.; VIEIRA L.R.; FARIA, B.N. Manipulação da composição do leite pela nutrição da vaca. In: SIMPÓSIO DO AGRONEGÓCIO DO LEITE: PRODUÇÃO E QUALIDADE (CD-ROM), 1., 2004, Belo Horizonte. Anais... Belo Horizonte: Escola de Veterinária da UFMG, 2004.

RIBAS, N.P.; HARTMANN, W.; MONARDES, H.G.; ANDRADE, U.V.C. Sólidos Totais do leite em amostras de tanques nos estados do Paraná, Santa Catarina e São Paulo. Rev. Bras. Zootec., v.33, p.2343-2350, 2004.

RIBEIRO NETO, A.C.; BARBOSA, S.B.P.; JATOBÁ, R.B. et al. Presença de Células Somáticas em Leite de Tanques no Estado de Pernambuco. In: $47^{\text {a }}$ Reunião Anual da Sociedade Brasileira de Zootecnia, Salvador, 47., 2010, Salvador. Anais Cd... Salvador: UFBA, 2010, 3p.

SCHUKKEN, Y.H.; BUURMAN, J.; BRAND, A. et al. Population dynamics of bulk milk somatic cell counts. J. Dairy Sci., v.73, p.13431350. 1990.
SHOOK, G.E.; SCHUTZ, M.M. Selection on somatic cell score to improve resistance to mastitis in the United States. J. Dairy Sci., v.77, p.648-658, 1994.

SILVA, V.P.R.; PEREIRA, E.R.R.; AZEVEDO, P.V. et al. Análise da pluviometria e dias chuvosos na região Nordeste do Brasil. Rev. Bras. Eng. Agri. Ambien., v.15, p.131-138, 2011.

SOUZA, G.N.; PAIVA E BRITO, M.A.V.; LANGE, C.C. et al. Qualidade do leite de rebanhos bovinos localizados na Região sudeste: Espírito Santo, Minas Gerais, Rio de Janeiro, Janeiro/2007 a Junho/2008. In: CONGRESSO BRASILEIRO DE QUALIDADE DO LEITE, 3., 2008, Recife. Anais... Recife, 2008, 373 p.

STAINES, V.; RUSSEL, B.; GALLAGHER, S. Factors affecting milk composition. Agriculture Western Australia, Farmnote 5/92. Revisão setembro 2000. Disponível em <www.agric.wa.gov.au>. Acessado em: 30 ago. 2009.

STATISTICAL Analyses System - SAS. User's guide: statistics. Cary: 2002.

ZOCCAL, R.O. Brasil produziu 30 bilhões de litros em 2010. Panorama do Leite on line, Ano 6, n.62, 2012. Acessado em: http://www.cileite.com.br/content/o-brasilproduziu-30-bilh\%C3\%B5es-de-litros-em-2010 